\title{
Rancang Bangun Sistem Informasi Helpdesk IT Support Berbasis Website
}

\author{
Yosua Liharja ${ }^{1}$, Ani Oktarini Sari ${ }^{* 2}$, Arief Satriansyah ${ }^{3}$ \\ 1,23Program Studi Sistem Informasi,Universitas Bina Sarana Informatika \\ *nioktari@gmail.com
}

\begin{abstract}
Abstrak
Kecepatan dalam memberikan pelayanan dari bagian IT support dalam membantu penanganan masalah yang berhubungan dengan perangkat komputer maupun jaringan internet ataupun intranet disuatu perusahaan sangat penting dalam menunjang efektifitas kerja. PT Markindo Rekateknik merupakan perusahaan yang bergerak dibidang mesin marking, coding printers dan mesin packaging. Dalam penanganan permintaan akses jaringan maupun perbaikan perangkat komputer masih dilakukan secara manual dan membutuhkan proses tersebut membutuhkan waktu yang lama karena perlu mendapatkan persetujuan pimpinan. Hal ini tentu saja dapat menimbulkan masalah yang berupa data laporan terlewat untuk dikerjakan, susah dalam melakukan pencarian data, dan resiko kehilangan data. Dan dalam hal monitoring permintaan akses dan kendala perangkat komputer dan jaringan yang sering dikomplain dalam 1 bulan tidak terekam dengan baik, sehingga menyulitkan untuk proses evaluasi dari kendala tersebut. Untuk itulah diperlukannya sistem informasi helpdesk untuk bagian IT Support yang terkomputerisasi dan dapat diakses dimana saja dengan koneksi internet, agar permasalahan yang ada dapat teratasi dengan baik. Dan proses monitoring dan laporan terhadap permintaan akses dan kendala perangkat komputer dan jaringan dari komplain yang disampaikan dapat terpantau dengan baik dan dapat dievaluasi untuk pencarian solusi yang tepat.
\end{abstract}

Kata kunci: helpdesk, IT Support, sistem informasi helpdesk berbasis website

\begin{abstract}
The speed of providing services from the IT support department in helping to handle problems related to computer devices or internet or intranet networks in a company is very important in supporting work effectiveness. PT Markindo Rekateknik is a company engaged in marking machines, coding printers and packaging machines. Handling requests for network access or repairing computer equipment is still done manually and this process takes a long time because it needs to get approval from the leadership. This of course can cause problems in the form of missing data reports, difficulty in searching data, and the risk of data loss. And in terms of monitoring access requests and computer and network equipment problems that are often complained of in 1 month, they are not recorded properly, making it difficult for the evaluation process of these obstacles. For this reason, we need a helpdesk system for the IT Support section that is computerized and can be accessed anywhere with an internet connection, so that existing problems can be resolved properly. And the process of monitoring and reporting on access requests and computer and network equipment constraints from submitted complaints can be monitored properly and can be evaluated to find the right solution..
\end{abstract}

Keywords: helpdesk, IT Support, website-based helpdesk information system 


\section{Pendahuluan}

Pemanfaatan teknologi komputerisasi dapat membantu proses kinerja yang berhubungan dengan data menjadi lebih terorganisir dengan baik. Akses yang serba cepat dari teknologi informasi membuat semua bidang usaha untuk memberikan pelayanan yang cepat bagi para pelanggannya. Bukan hanya pada kualitas pelayanan tetapi juga pada kecepatan pelayanan yang efisien dalam menyampaikan informasi, sehingga peningkatan kinerja perusahan dapat dicapai [1]. Penggunaan teknologi berbasis website kini makin banyak dimanfaatkan dan bisa dikatakan telah menjadi suatu kebutuhan penting dalam mempermudah penyampaian suatu informasi dengan cara efektif yang dapat di akses kapan saja, dimana saja dan oleh siapa saja melalui media internet [2]. Website digunakan untuk menampilkan informasi teks, gambar diam atau bergerak, suara, animasi, atau gabungan dari semuanya [3]. Penggunaan komputer dalam sistem informasi tidak lepas dari penyediaan sarana berupa Software (Perangkat lunak) dan Hardware (Perangkat keras) yang memiliki kecepatan proses yang memadaisebanding dengan tingkat pekerjaan, serta penyediaan Brainware (Manusia), User (Pengguna) dan Sumber Daya Manusia (SDM) yang menjalankan sistem tersebut agar peningkatan perbaikan sistem dapat digunakan oleh stakeholder [4]
Sistem informasi helpdesk diharapkan dapat mengatasi permasalahan dan memberikan layanan terhadap seluruh permasalahan baik yang bersifat internal maupun seluruh permasalahan operasional aplikasi ataupun halhal yang berhubungan dengan sistem dan teknologi informasi [5].

PT Markindo Rekateknik adalah perusahaan swasta yang bergerak dibidang dibidang mesin marking, coding printers dan mesin packaging, dalam melakukan Helpdesk yang berkaitan dengan IT support seperti instalasi dan update software, permintaan perangkat komputer, konsultasi permasalahan perangkat komputer yang bermasalah serta request akses hak akses sharing jaringan maupun perangkat komputer yang terhubung, masih dilakukan dengan cara menggunakan formulir request IT support yang belum terkomputerisasi [6]. Dalam proses berjalan tersebut, masih diajukan melalui kertas formulir yang prosesnya membutuhkan waktu yang lama karena perlu adanya persetujuan dari pimpinan divisi. Selain proses yang lambat, resiko untuk laporan dari karyawan yang membutuhkan terselip atau tidak sampai ke bagian it support karena berkasnya hilang. Dan proses monitoring tidak adanya perekapan laporan komplain dalam satu periode tertentu [7] terhadap request akses maupun perangkat komputer tidak terdata dengan akurat, sehingga saat diperlukan datanya untuk evaluasi data tersebut tidak ada 
Untuk itulah dibutuhkannya sebuah sistem informasi helpdesk untuk membantu bagian IT support dalam merespon permintaan-permintaan yang ada dari karyawan/user. Dan penyimpanan serta oganisir data menjadi lebih baik lagi dan laporan dari masing-masing kategori dapat di evaluasi agar dapat memberikan solusi yang optimal. Dan sistem informasi yang dibangun berbasis website, karena data dan informasi yang disampaikan melalui website dapat diakses lebih mudah dan tersebar lebih cepat sehingga lebih efisien [8]

\section{Tinjauan Pustaka}

\subsection{Penelitian Terkait}

Herfandi, Yuliadi, Sultan Naufal Abdillah, Eri Sasmita Susanto melakukan penelitian dengan judul Rancang Bangun Sistem Informasi Pengaduan Layanan Sarpras Di Universitas Teknologi Sumbawa Berbasis Web, tujuan penelitian ini agar memudahkan civitas akademika di Universitas Teknologi Sumbawa dapat melaporkan kerusakan dan memberikan saran serta masukan terhadap pelayanan dan fasilitas sarana dan prasarana yang ada di universitas tersebut. Dilihat dari proses yang berjalan permasalahannya adalah civitas akademika di Universitas Teknologi Sumbawa dapat melaporkan kerusakan dan memberikan saran serta masukan terhadap pelayanan dan fasilitas sarana dan prasarana yang ada di universitas tersebut. Sehingga implementasi Sistem informasi pengaduan layanan sarpras Universitas Teknologi Sumbawa dapat digunakan oleh Biro Sarana dan Prasarana dan Civitas Akademika UTS untuk membuat dan mengatur pengaduan [9]. Penelitian yang dilakukan oleh Lia Mazia, Lilyani Asri Utami, Febi Karina Bintang dengan judul Rancang Bangun Sistem Informasi Helpdesk Ticketing Berbasis Web pada PT. Mitra Tiga Berlian Bekasi, Tujuan penelitian ini adalah untuk mengevaluasi sistem pelaporan yang berhubungan dengan IT support. Dilihat dari proses yang berjalan permasalahannya adalah tidak terdatanya antrian proses penanganan keluhan pada bagian IT support sehingga komplain dari karyawan tidak jelas statusnya apakah sedang diproses, ditolak atau dipending. Untuk itulah dibangun sistem aplikasi helpdesk ticketing yang berbasis website supaya dapat mengupayakan dalam kemudahan dalam proses dokumentasi laporan gangguan teknologi informasi pada PT. Mitra Tiga Berlian [10]. Pada penelitian yang dilakukan oleh Rika Novita Wardhani, Meinarini Catur Utami, Ibnu Yahya Saputra yang berjudul Sistem Informasi Helpdesk Ticketing Pada PT. Bank Mega Tbk terdapat permasalahan dalam sistem berjalan dimana proses pengolahan helpdesk ticketing masih manual dalam melakukan perkerjaan, karena sistem helpdesk ticketing yang belum terkomputerisasi sehingga berjalan tidak optimal, 
DOI : 10.29408/jit.v5i1.4738 Link : https://dx.doi.org/10.29408//jit.v5i1.4738

meskipun permasalahan dapat diselesaikan namun memakan waktu yang lama karena dilakukan secara manual sehingga proses tidak terkontrol dan sering terjadinya duplikasi data [11] . Dalam penelitian yang dilakukan oleh M Jundi Hakim, Cep Adi Wiharja, Ishak Kholil dan Ahmad Sinnun dengan judul Implementasi Sistem Informasi Helpdesk Berbasis Web Pada SKK Migas, mendapatkan kesimpulan dalam penelitian yang dilakukan yakni dengan melakukan pembuatan website Dokumen manajemen laporan kerja Pada SKK Migas ini dilihat dari aspek manajerial mempermudah berbagi informasi kepada divisi lain dan jika dilihat dari aspek sistem dapat membuat penyimpanan dokumen laporan lebih tertata dan berurutan, serta dapat mempersingkat waktu divisi lain dalam mendapatkan informasi [12]. Penelitian dengan judul Perancangan Sistem Informasi Helpdesk Menggunakan Website Design Methode dalam mendukung Tata Kelola Teknologi Informasi yang dilakukan oleh R Wisnu Prio Pamnungkas, Allan D Alexander dan Ali Reza menghasilkan dengan adanya penggunaan aplikasi helpdesk dalam penerapan manejemen insiden pada domain ITIL Service Operation, aplikasi dapat menampung data keluhan dan permasalahan yang dihadapi oleh pelanggan dan diteruskan kepada staff yang bersangkutan. Dari aplikasi pun dihasilkan grafik yang dapat membantu mengetahui jumlah SLA yang sering dilanggar, banyaknya tiket yang ditutup dan tiket yang telah diinput kedalam sistem [13]

\subsection{Landasan Teori}

a. Rancang Bangun

Arti rancang bangun menurut Pressman adalah proses tahapan prosedur untuk mengartikan hasil dari analisa sistem berjalan ke dalam bahasa pemrograman untuk mendeskripsikan dengan detail bagaimana komponen-komponen sistem diimplementasikan [14].

\section{b. Sistem Informasi}

Sistem informasi adalah hasil dari penyatuan banyak elemen yang saling terhubung dengan cara mengumpulkan atau disebut input, memanipulasi yang disebut process, menyimpan, dan juga mendistribusikan atau disebut output suatu data atau informasi yang dapat mengakibatkan reaksi atau mekanisme feedback sehingga memenuhi suatu tujuan [15]

c. Sistem Informasi Web

Sistem informasi berbasis web merupakan sistem informasi yang berbentuk website yang dalam penggunaannya memanfaatkan teknologi internet [16]

\section{d. Website}

Menurut Abdulloh R, Website atau disingkat web, dapat diartikan beberapa halaman di internet yang berisi informasi dalam bentuk data digital baik berupa text, gambar, video, suara dan animasi lainnya [17] 


\section{e. Helpdesk}

Helpdesk sebagai bagian utama dari fungsi layanan, bertanggung jawab mempertemukan sumber daya untuk menyelesaikan masalah. [18]

\subsection{Tahapan Penelitian}

Dalam tahapan penelitian pengembangan perangkatlunak yang dilakukan dalam rancang bangun sistem informasi helpdesk IT support berbasis website ini menggunakan model waterfall. Tahapan penelitian digambarkan sebagai berikut :

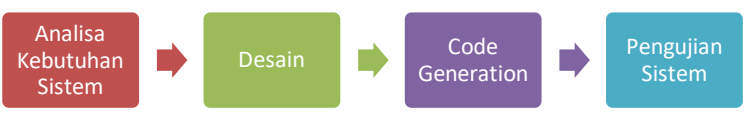

\section{Gambar 1. Tahapan Penelitian}

Penjelasan tahapan penelitian berdasarkan gambar 1 adalah sebagai berikut :

a. Analisa Kebutuhan

Menganalisa kebutuhan apa saja yang dibutuhkan dalam pembuatan sistem informasi helpdesk IT support berbasis web menggunakan model waterfall, diantaranya bentuk dokumen formulir request perangkat maupun akses jaringan yang akan diimplementasikan ke website.

b. Desain

Membuat perancangan sistem informasi helpdesk IT support berbasis website meliputi desain sistem menggunakan UML untuk desain database menggunakan ERD. c. Code Generation

Bahasa pemrograman web yang digunakan PHP dan framework Codelgniter, text editor mengggunakan Microsoft Visual Studio Code, dan database MySQL

d. Pengujian Sistem

Pengujian dari segi fungsional dilakukan untuk memeriksa apakah masih ada kekurangan atau kesalahan dari tahap coding. Pengujian dilakukan dengan menggunakan blackbox testing.

\section{Metode Penelitian}

3.1. Teknik Pengumpulan Data

Penulis melakukan pengumpulan data melalui cara:

\section{Observasi}

Penulis melakukan pengamatan-pengamatan langsung pada PT.Markindo Rekateknik. Hasil pengamatan langsung dicatat guna dijadikan referensi perbaikan sistem berjalan

\section{Wawancara (Interview)}

Penulis menanyakan langsung kepada bagian IT sehingga diperoleh penjelasan kebutuhan dari sistem helpdesk IT support .

\section{Study Pustaka (Library Reseach)}

Selain melakukan melakukan studi kepustakaan melalui informasi, jurnal ilmiah, buku dan referensi literatur lainnya yang berhubungan dengan tema penelitian. 


\subsection{Lokasi Penelitian}

Penelitian ini dilakukan dengan mengumpulkan sumber data yang berada di PT Markindo Rekateknik, Graha Arteri Mas 2, Jakarta Barat.

\section{Hasil dan Pembahasan}

1. Desain Sistem

a. Use Case Diagram Admin

Dalam menjelaskan alur kerja Admin didalam sistem helpdesk dapat dilihat dalam gambar 2 use case diagram akses Admin

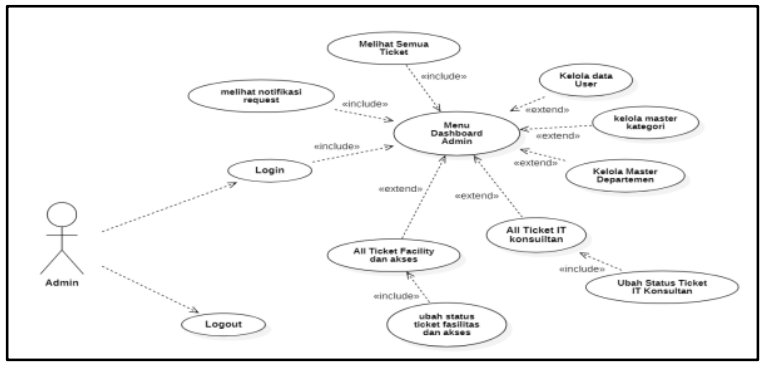

Gambar 2. Use Case Diagram Admin

\section{b. Use Case Diagram Kepala Divisi}

Dalam menjelaskan alur kerja kepala divisi didalam sistem helpdesk dapat dilihat dalam gambar 3 use case diagram akses Kepala Divisi

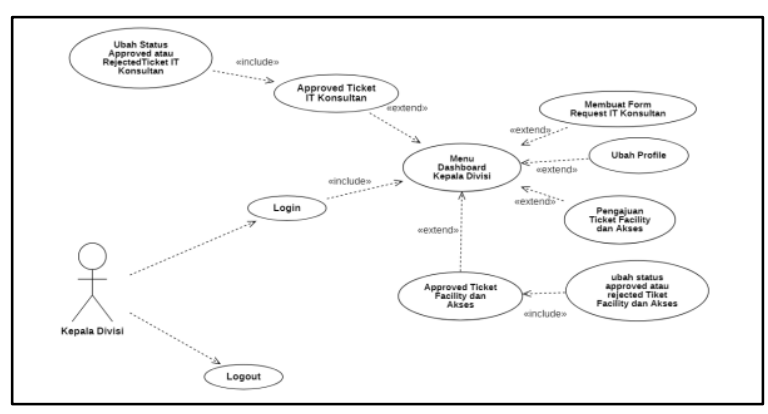

Gambar 3. Use Case Diagram Kepala divisi c. Use Case Diagram Karyawan

Dalam menjelaskan alur kerja karyawan didalam sistem helpdesk dapat dilihat dalam gambar 4 use case diagram akses Karyawan

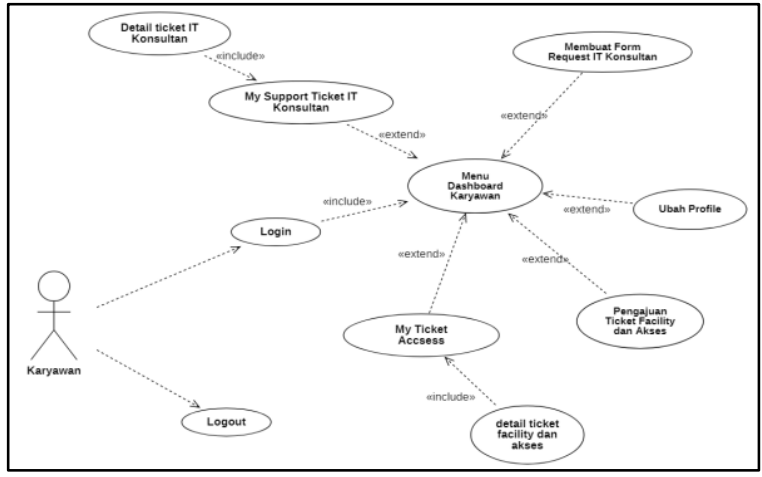

Gambar 4. Use Case Diagram Karyawan

d. Activity Diagram Alur Open Ticket IT Konsultan Dalam menjelaskan alur open ticket IT Konsultan didalam sistem helpdesk dapat dilihat dalam gambar 5 activity diagram alur open ticket IT Konsultan

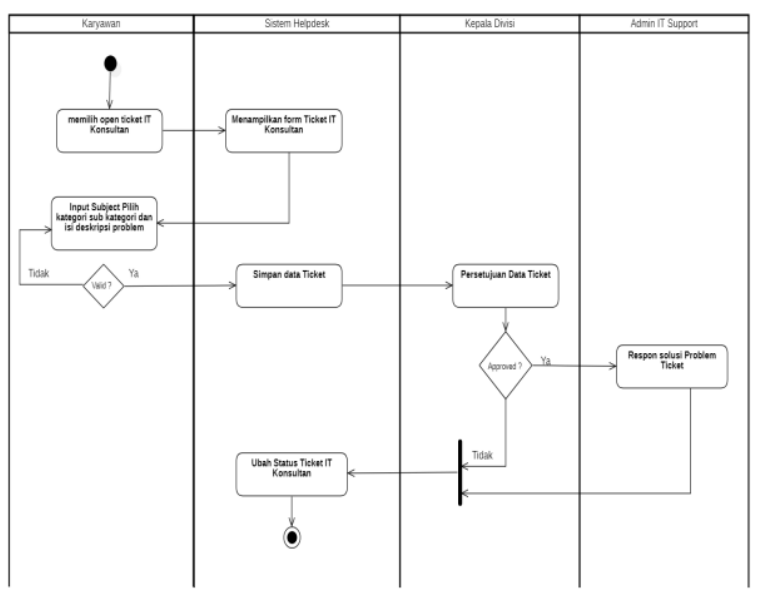

Gambar 5. Activity Diagram Alur Open Ticket IT Konsultan 
2. Desain Database

\section{Entity Relationship Diagram (ERD)}

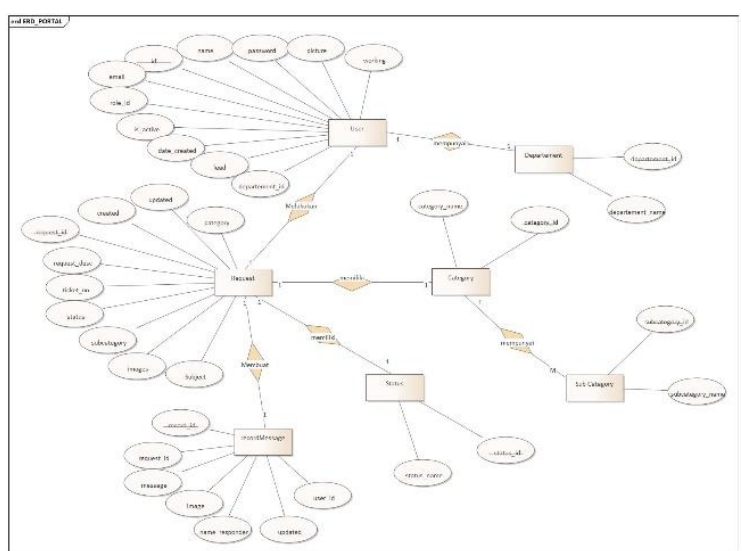

Gambar 6. Entity Relationship Diagram (ERD)

\section{Desain User Interface}

Berisikan implementasi hasil rancangan user interface yang dibuat tentang sistem informasi helpdesk it support berbasis website adalah sebagai berikut :

\section{a. Halaman Login}

User melakukan login terlebih dahulu sebelum dapat mengakses modul modul yang ada pada sistem dan setelah berhasil login user dapat mengakses menu sesuai dengan role hak akses user.

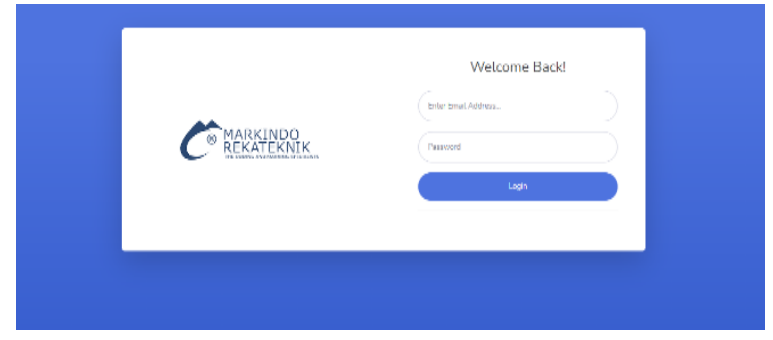

Gambar 7. Halaman Menu Login

b. Halaman Dashboard Admin

Di sini merupakan halaman pertama setelah admin login di dashboard admin dapat melihat status tiket open yang menandakan untuk di tindak lanjutkan dan on progress yang merupakan status yang sedang di kerjakan saat ini

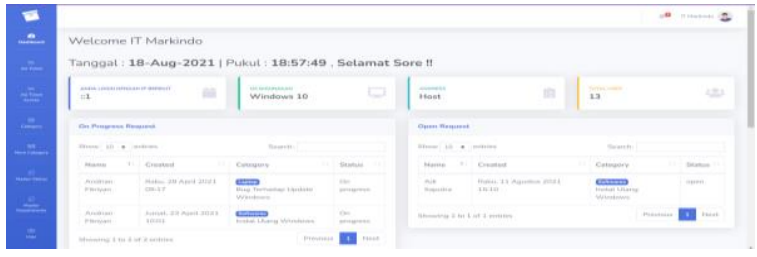

Gambar 8. Tampilan Halaman Dashboard Admin

c. Halaman Dashboard User

Di sini merupakan halaman pertama setelah user login di dashboard user.

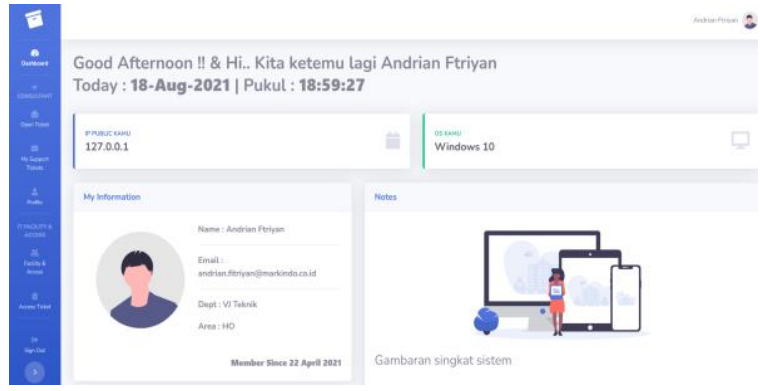

Gambar 9. Tampilan Dashboard User

d. Halaman Dashboard Kepala Divisi

Di sini merupakan halaman pertama setelah user login di dashboard user.

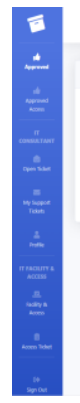

\section{Gambar 10. Tampilan Dashboard User}

e. Tampilan Menu Aprroved

Di halaman ini dapat di lihat ada modul bernama approved di sini digunakan untuk 
mengubah status tiket user memberikan persetujuan sehingga tiket dapat berubah status menjadi open dan di tindak lanjutkan tim IT.

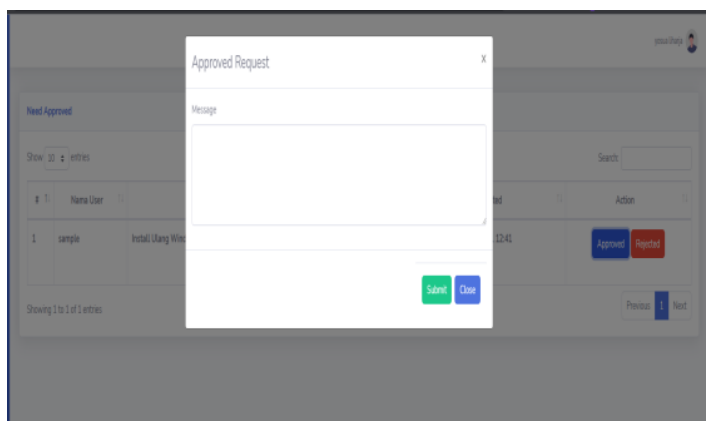

Gambar 1. Tampilan Menu Approved

f. Tampilan Menu Rejected

Di halaman ini dapat di lihat ada modul bernama Rejected di sini digunakan untuk mengubah status tiket user memberikan memberikan penolakan jika tiket kurang memenuhi syarat persetujuan.

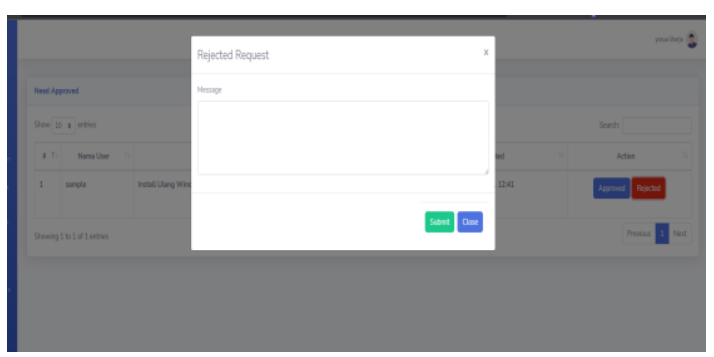

Gambar 2. Tampilan Menu Rejected

\section{g. Menu Form Request}

Di halaman ini merupakan halaman yang dapat di akses oleh user karyawan maupun kepala divisi di sini user dapat mengajukan request terakit keperluannya namun ada perbedaan untuk user karyawan di wajibkan melewati step approved namun untuk kepala divisi, tiket yang di buat statusnya open tanpa melewati approved lagi

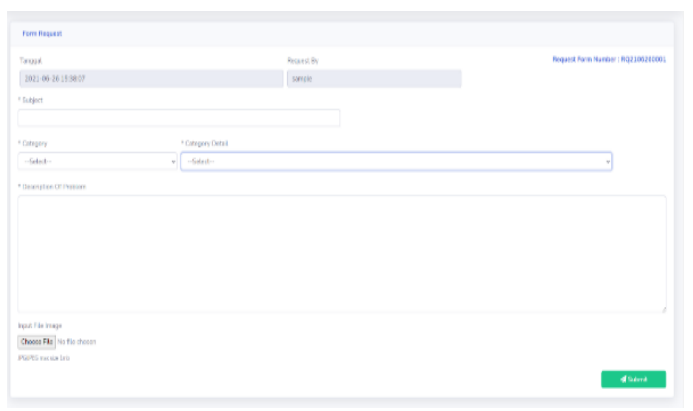

Gambar 3. Halaman Menu Form Request

h. Halaman All Tiket Request

Ini merupakan halaman modul admin di mana admin dapat melihat dan menindak lanjutkan tiket yang di buat user

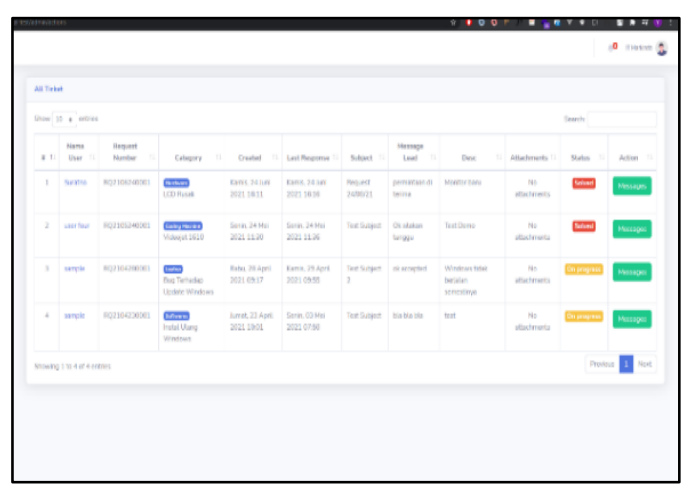

Gambar 4. Halaman All Tiket Request

\section{h. Halaman Diskusi}

Halaman ini merupakan bagian dimana user dan admin dapat berdiskusi hingga problem ataupun request teratasi, di halaman ini yang dapat merubah status tiket hanya pihak admin dimana jika status solved tiket akan di tutup 


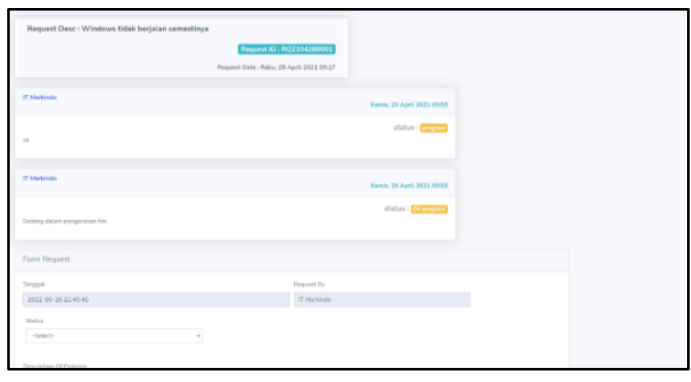

Gambar 5. Halaman Diskusi

\section{Kesimpulan}

Berdasarkan pembuatan sistem informasi helpdesk IT Support pada PT Markindo Rekateknik Persada ini, maka dapat disimpulkan yakni sistem informasi tersebut memudahkan pengaturan data, mempercepat proses dari sistem manual, dapat melihat tracking masalah dan mencari solusinya, dalam pengolahan data dapat lebih efisien dan mudah dalam mengaksesnya. Pengembangan sistem informasi kedepannya dapat ditambahkan fitur-fitur yang belum terdapat dalam dalam website saat ini.

\section{Daftar Pustaka}

[1] P. Utomo and B. Remiaditya, "Sistem Informasi IT Support Berbasis Web pada PT. Softex Indonesia Tangerang," JURNAL SISFOTEK GLOBAL, vol. Vol. 3 No. 1 / Maret 2013, 2013.

[2] S. Suhartini, M. Sadali and Y. K. Putra, "Sistem Informasi Berbasis Web Sma Al- Mukhtariyah Mamben Lauk Berbasis Php Dan Mysql Dengan Framework Codeigniter," Infotek : Jurnal Informatika dan Teknologi, vol. 1, pp. 79-83, 2020.

[3] F. Febriansyah and S. Muntari, "Aplikasi Pencarian dan Pemesanan Hotel di Kota Pagar Alam Berbasis Web," Infotek : Jurnal Informatika dan Teknologi, Vols. Vol. 4 No. 2, Juli 2021, pp. 334-344, 2021.

[4] J. Junaidi, L. Anugrah and A. D. Pancasakti, "Model Aplikasi Monitoring Sistem Absensi Sidik Jari Sebagai Pendukung Keputusan Untuk Penilaian Kinerja Pegawai," in Konferensi Nasional Sistem \& Informatika 2015, 2015.

[5] E. Rivalni and F. Fitakwin, "SISTEM INFORMASI HELPDESK BERBASIS WEB MENGGUNAKAN METODE PROTOTYPE PADA PT DENSO MANUFACTURING INDONESIA," SIGMA Jurnal Teknologi Pelita Bangsa, vol. Volume 10 Nomor 4 Juni 2020, 2020.

[6] A. H. Arribathi and F. D. M. Rosita, "Desain Sistem Informasi Pelayanan Keluhan Jaringan pada Dinas Komunikasi dan Informatika Kabupaten Tangerang," SATIN - Sains dan Teknologi Informasi, Vols. Vol. 5, No. 1, Juni 2019, 2019.

[7] P. Mauliana, W. Wiguna and A. Y. Permana, "Pengembangan E-Helpdesk Support System Berbasis Web di PT Akur Pratama," JURNAL RESPONSIF, vol. Vol. 2 No.1 Februari 2020, pp. 19-29, 2020.

[8] Y. Yulianti, A. Saifudin, W. Haryono, A. F. Zulfikar and T. Desyani, "Pengembangan dan Sosialisasi Website untuk Meningkatkan Penyebaran Informasi SMP Islam Madinatul I'Imi Ciputat-Tangerang Selatan," KOMMAS: Jurnal Pengabdian Kepada Masyarakat, vol. 1, 2020.

[9] H. Herfandi, Y. Yuliadi, S. N. Abdillah and E. S. Susanto, "RANCANG BANGUN SISTEM INFORMASI PENGADUAN LAYANAN SARPRAS DI UNIVERSITAS TEKNOLOGI SUMBAWA BERBASIS WEB," JINTEKS (Jurnal Informatika Teknologi dan Sains), Vols. Vol. 3 No. 1, Februari 2021, 2021.

[10] L. Mazia, L. A. Utami and F. K. Bintang, "Rancang Bangun Sistem Informasi Helpdesk Ticketing Berbasis Web pada PT. Mitra Tiga Berlian Bekasi," Jurnal Informatika Universitas Pamulang, Vols. Vol. 6, No. 1, Maret 2021, pp. 85-89, 2021.

[11] R. N. Wardhani, M. C. Utami and I. Y. Saputra, "SISTEM INFORMASI HELPDESK TICKETING PADA PT. BANK MEGA Tbk," Jurnal IImiah MATRIK, vol. 22, no. No.2, Agustus 2020, 2020. 
[12] M. J. Hakim, C. Adiwiharja, I. Kholil and A. Sinnun, "Implementasi Sistem Informasi Helpdesk Berbasis Web Pada SKK Migas," Indonesian Journal on Networking and Security, vol. 8, 2019.

[13] R. W. P. Pamnungkas, A. D. Alexander and A. Reza, "Perancangan Sistem Informasi Helpdesk Menggunakan Website Design Methode Dalam Mendukung Tata Kelola Teknologi Informasi," Jurnal Sains Komputer \& Informatika (J-SAKTI), 2019.

[14] A. Irawan and N. K. Setyorini, "Rancang Bangun Aplikasi helpdesk Dengan Menggunakan Pendekatan Knowledge Management System Pada Seksi Teknisi PT. Indah kiat pulp \& paper tbk.," Jurnal ProTekInfo, vol. Vol. 4 |Agustus 2017, 2017.

[15] I. K. Raharjana, Pengembangan Sistem Informasi Menggunakan Metodologi Agile, Yogyakarta: Deepublish, 2017.

[16] H. Ahmadi and M. H. Nasution, "Rancang Bangun System Komputerisasi Penguatan Pelayanan Kelompok Penyelenggara Sanitasi Penyedia Air Minum (KPSPAM "DJ-Menteng") Desa Pendem Kec. Janapria," Infotek : Jurnal Informatika dan Teknologi, vol. 2, pp. 119-126, 2019.

[17] C. Carso, Y. Purwati, S. Gustin and A. P. Kuncoro, "Rancang Bangun Aplikasi Pengaduan Pelanggan Berbasis Web Menggunakan Framework Codeigniter $\mathrm{Di}$ Indotechno Purwokerto," Jurnal Sains dan Informatika, vol. 6, pp. 166-174, 2020.

[18] R. M. Bahrudin, M. Ridwan and H. S. Darmojo, "Penerapan Helpdesk Ticketing System Dalam Penanganan Keluhan Penggunaan Sistem Informasi Berbasis Web," JUTIS, vol. Vol. 7 No. 1 Bulan April 2019, 2019. 